\title{
Critical psychology and brain: Rethinking free will in the legal context
}

\section{Chetan Sinha ${ }^{1}$}

\begin{abstract}
The article draws from critical psychology to discuss the rising debate on brain determinism and free will in the legal domain. As free will also corresponds to the context and culture, it can have both the public and private space of expressions. The rise of neuroscience and its influence in the legal domain offers a holistic and sociocultural meaning of responsibility. Even one becomes entitled to take free will as a 'necessary illusion' in order to be in the zone of 'moral as well as legal-social life forming activities'. In the criminal justice system free will is not taken as any kind of necessary illusion but the conscious will and action of the person. This further throw light on how self-regulation directs oneself to the wilful control of illegitimate acts and the role of brain.
\end{abstract}

Society matters in both the expression of acts and the kind of determinism approved by the legal domain such as the inputs from the forensic and neurosciences to build up the case for the legal agents. What is required for us to understand is the consistency and genuineness of a person across the time and place, both private and public. The discussion about questioning the meaning of private and public space is out of scope here, however, these are taken, as the word suggests in the general societal terminology, and this is what legal domains also affirm. If the person holds the intention privately to act against the social norms but due to the societal and legal fear doesn't commits the act, this kind of thinking doesn't have any substantiation. His being in the social world is similar to the person who doesn't hold any intention to act against the norm under the periphery of law. The act committed in the private space or the public is a crime and taken as a wilful act by the law. So, the private space and private intentions are two dissimilar things where any act committed in the private space is a public matter and hence the legal matter. Private intention matters in concomitance with the witnessed behaviour (Ajzen \& Madden, 1986), though the correlation between the two has to be established with the best possible corroborative techniques. Understanding the intentions of others action is just not inferring about the person's qualitative state of mind which is proven to be difficult to understand, but it is the inference out of the observer's own subjectivities. It is the intention of

\footnotetext{
${ }^{1}$ OP Jindal Global University, Sonipat. Email: sinchetan@gmail.com

Dr. Chetan Sinha, OP Jindal Global University, Sonipat

Email: sinchetan@gmail.com
} 
the observer which may have led to the action inferred upon the other who already committed the action.

In the criminal justice system, free will is paramount which is taken as the reason behind controlling or committing the action. Libet's (1985) experiment showed that conscious will is illusion and the person's free will, if any, may not initiate a voluntary act but may control it. Free will is seen in all of us to control one's action which is not approved or has past unpleasant consequences. A child may not bully the other child, if he has witnessed some unpleasant consequence of doing so or his actions of bullying others has been transformed by teachers' positive intervention like, blurring the socioemotional boundaries between the two. This kind of finding, as Libet stated, will also affect guilt and responsibility (p. 47). Can Soul, mind, free will and responsibility be real entities or they are simplified linguistic representatives of some deeper collectively known inferences. "He is a nice soul" ---what does it mean? Are there any objective criteria on the basis of which any person has full responsibility and reduced responsibility? Why does it get reduced and on what basis? On what platform does the legality/law stand: action, responsibility, free will, intention, reason and rationality? What are the sufficient and necessary conditions on the basis of which defendant is guilty? Is it action and responsibility, intention and free will altogether which the individual lives?

We usually infer the cause on the basis of effect. In the legal domain we can't start with cause as we don't have the knowledge of the effect. So, unless effect is not observed we can't go into the cause. For example, just by seeing the people around we don't unnecessary fall into the legal meaning making and consciousness, unless some non-normative or unconventional behaviour is observed, someone commits any illegal acts on the victim, and then causes are inferred, and placed in the arena of intentionality and reasoning. Though we attribute stereotypically that any kind of person may be causing this effect based on the past experience but that is amenable for scrutiny. However, how our assumptions are framed and what are the dominant paradigms shaping our knowledge depends upon our ways of seeing law and its intenalization.

Is their difference between different kinds of law, for example, physical laws, or social laws? Since physical laws based on the natural science observations and arguments based on the objective measurement are also overridden by new theories and so the social laws. According to Kolber (2017) "Over reliance on the mechanistic causes weaken our intuitions about the responsibility" and "free will sceptics say that the reduced responsibility reaction does not go far enough" (P. 12). At the same time Kolber (2017) further extended the 
antinomies of free will as "the ability to freely choose $\mathrm{X}$ arguably implies the ability to choose not- $X$. But if we cannot alter the forces that cause us to choose $X$, then it is not clear we really could choose not- $\mathrm{X}$, and it is not clear we really have the kind of control over our choices necessary for moral responsibility" (P.13). Some of the questions which need an answer pertaining to the notion of free will in the legal domain and at the general societal level are as follows: Are reasons the author of moral precepts (Kant ${ }^{2}$; see Lakoff \& Johnson, 1999)? Are their universal ethics? Can strict father family morality be internalized as the basis of universe rational morality and moral laws? Does Free will tally with the intentions? Are free will expressive in the form of different actions?

Kolber (2017) stated about the duality that overpowered the law in "the laws dualistic view of mind and brain" (Kolber, 2017; p.14). He showed one recent study in which 75 percent of college students in the United States deemed moral responsibility incompatible with determinism. So too in the other three countries that were part of the study such as India (72\%), Hong Kong (63\%), and Colombia (68\%). Numerous important and interesting writings had been done on free will, moral responsibility and determinism (e.g., Fischer, Kane, Pereboom \& Vargas, 2007; Kenny, 2011; Baumeister, 2008; Baumeister, Mele \& Vohs, 2010). The techniques have its value, and it gives life to the brain by the interpretations of the correlations between brain activities and behaviour. Image of the brain has to be there to make its understanding better, but in everyday life, it does not happen and what we mostly construct is something beyond the mind, and embedded in the understanding of the social relationships and the discourses. The first thing any inspector doubts about is the actual cause of the event. It is another matter that the method utilized to explore the cause may be insufficiently lacking the rigour to handle the aura of the cause, which may be nothing but the attraction of the cause taken as true cause. Isaiah Berlin's question about the meaning of liberty as 'What is it like to be autonomous and in what capacity?', becomes important to understand the history of free will in the legal decision making and how the determinism was either adopted in the compatibilist mode or rejected all together ${ }^{3}$, though some of the scholars placed free will in an order of the system under which free will operates, as without that order of systems, free will loses its meaning and that exactly form the basis of legal norms ${ }^{4}$.

\footnotetext{
2 https://plato.stanford.edu/entries/kant-moral/

3 see Isaiah Berlin "The two concepts of liberty"

${ }^{4}$ Paul Kahn (2019). Project and system: There are two ways of seeing order in the world: as a spontaneous system or as an intentional project. Which way lies freedom? In Aeon Magazine (9 December, 2019).

Dr. Chetan Sinha, OP Jindal Global University, Sonipat

Email: sinchetan@gmail.com
} 


\section{Social responsibility and the capacity to be rational}

The concept of responsibility based on the capacity for rationality connects with our most fundamental convictions about human nature and human dignity and our everyday experience of guilt and innocence and blame and punishment (Pardo \& Patterson, 2017). What is it like to be responsible? Are we machines simply responding to neural activities in the brain? Is it possible for humans to practically survive without agency, free will and normativity? What is the role of reason in making a choice? If reason is property of thought and agency and not the property of brain, then what is dignity of the mind and brain? Reducing one's agency to the brain may be in-dignifying to the human agency as a whole and to the wider society. Human agency and existence are a matter of dignity. Though the dignity of humans is embedded in the power context where the role of market, individuality, and capitalism has framed the notion of free will. In the current time law has witnessed the changed meaning of rationality. Earlier, the duality of pure soul and impure body which devised the penal code for punishment in the mediaeval times where more catering to the absoluteness of the power of sovereignty inherited in the king where will and rationality of the person was congruent with the sovereignty.

Foucault (1977) indicated in 'Discipline and Punish' that free will was the matter of body and soul, where soul was saved by succumbing the body of the criminal to severe torture. Torture is also a kind of imposition of will of the state or perpetrator in order to destroy the normative world of the victim (Cover, 1986). Though this doesn't result in the elicitation of information. In the word of Cover (1986), torture is "the deliberate infliction of pain in order to destroy the victim's normative world and capacity to create shared realities" (p. 1603), where "victims intangible normative world has been crushed by the material reality of pain and its extensive fear" (Scarry, 1985). In order to deal with the sufferer's self (Scarry, 1985) the deliberate infliction of pain from the state only incapacitate the bearer's self and identity, as a form of political prisoner or criminal, and override it with the determinism or a kind of new form of will where things are not going to be in the victims favour and he has to bear the pain which is determined and imposed, where there is no control over one's body, memory, and self. The victimization of the others self is another form of understanding about the clash between determinism and free will. So, in one-way determinism and free will are not easy contenders and one can take the place of another depending upon the context (e.g., the context of political ideology and the criminalization of the victim holding different political orientations). 
The current times had embraced determinism in a different way, as the division of human into dual system of body and soul has been turned down as irrational in the modern times and a new meaning of determinism has incapacitated the old meaning of determinism. The modern time in the wake to redefine the meaning of responsibility in law, making it more humane is working upon the pragmatic aspect of free will where it conceptualizes free will on the features collected from the observations, forensics details, linguistic categories, legal semantics derived through the legal informatics and at the robust level from neuroscientific expertise. Free will thus is conceptualized more on the line of in-compatibilism as retained on the basis of past appropriation of social symbols in our society, in terms of individual deeds and the equivalent outcomes. Free will is in the capacity of the person to bring his rationality in forefront either in terms of controlling one's action ${ }^{5}$ or acting out to the expectation of society. The intensity of punishment aligned to the criminal act may vary across the culture depending upon how people and judges see the actions in terms of the individual's intentions. In other ways, how intentions are constructed in the folk psychological understanding based on the observed actions. Free will in itself says nothing unless it is carried forward in action.

The Foucault's assumption about the people will in their participation in the game of power (see also Teo, 2015) paradoxically impinge upon his version of resistance, a form of free will in which power is questioned and the identity of the group becomes more pronounced in offering veto to the will of the powerful. However, this agency of the people to offer resistance was itself constituted by the power and any possibility that it is an independent source of resistance was ironically regulated by the will of power (Feltham \& Clemens, 2003; see Hook, 2007). The interdisciplinary analysis of free will may evoke varieties of situations in which it is possible to either account for the society, history and discourses as a marker of neural changes and responses or only the receptive capability of the brain to shape the meaning of behaviour according to the societal standards. We need to resolve this incompatibility of disciplinary analysis where we can have a better understanding of the point of intersection where these divergences of opinion meet.

The neuroscientists and psychologists' atomism together with the broad assumption about human social interaction and discourse seems to be on different tracks to understand the meaning of individual, society and law. How can we provide a better picture of this by following separate tracks, and in actuality, we humans live by that everyday sociality and our individuality, so a compatibility is possible between these tracks? The link formed between

\footnotetext{
${ }^{5}$ See Principles of alternate possibilities

Dr. Chetan Sinha, OP Jindal Global University, Sonipat

Email: sinchetan@gmail.com
} 
action and the individual purpose is a societal assumption based on the collective selves on the basis of which theory about the intention is built up. The whole arena of legal domain shows the dominance of responsibility of individuals if he/she acts contrary to the established will of the society. How does one anomaly of neuroscientific defect or insanity may drive the whole law domain into the shift in the meaning of its legal categories? Free will has occupied our mind in the actual business place.

Law is a formalized public arena where deterministic constructs hardly surpass the everyday cognition of the legal agents who are freely willed, responsible and conscious agents. The rationality of the person is symbolized through his/her normal acts and it is rare to see the person acting abruptly and consistently across the situation defying the social norms which is actually taken in consensus by the collectively rational agents as insane. Even the action which is contrary to the social consensus or the normal way of living can be categorized as insane, for example, even the act of injury or fraud. The question is not about the existence of free will, if it exists, it does so. What matters is the perception about one's action as freely chosen or regulated by something obvious and tangible. Some of the researchers (e.g., Shariff, Schooler, \& Vohs, 2008; Vohs \& Schooler, 2008) speculated through the experimental study that it is the belief of the people in free will that matters in their action. The existence of free will in an objectified and observable manner can be a myth and for some it is a creation of the social and political system under which the acts of the person is labelled as responsible and intentional. Even the belief about the existence of free will is not naturally and universally adopted, as being natural and universal can be the induced effect of the space and time under which a person makes sense of his/her world, and very much constrained or facilitated by the priming context. For example, in one study people endorsed incompatibilism between determinism and freewill when given the abstract account of a deterministic universe (Nichols, \& Knobe, 2007) and in the other study people endorsed compatibilism when given concrete account of a deterministic universe (Nahmias, Morris, Nadelhoffer, \& Turner, 2005). To understand the 'intuition regarding the conditions for free will and moral responsibility across culture', Hannikainen et al. (2019; p. 2) examined people from 21 diverse locations across the world. It was noticed that 'despite lacking alternate possibilities, the perpetrator (people actions in different situations of alternative sequence and counterfactual intervener) was seen as acting freely by a significant majority of participants (p. 5). It was also observed that free will may not correspond to the lack of alternative possibility (Frankfurt, 1969). 
Any action in a context supposedly has the possibility to be not acted out unless the person willed. However, cultural difference was prominently observed in the import of source hood for free will (Pereboom, 2001) in the case of normal choice making such as taking a lunch as compared with the case of killing someone, whatever was the intervening circumstances where most of the people (American, European and middle eastern) attributed the blame and agreed with harsher punishment on the perpetrator, as the actor is seen as exercising greater perceived control over their action (Fischer, Kane, Pereboom, \& Vargas, 2007). Though for Asians blame and punishment was equally directed towards the perpetrator in deterministic and free will situations, despite viewing the actors as an element of extrinsic and situational pressures. The belief about the free will seems to be more strongly observed when the observer perceives the exercise of control within the actor. However, in our everyday work and social life we hardly notice how much we are driven by subtle situational cues. Our acts, speeches, body languages and self-reflection are all somewhere as advocated by neuroscientists are the brain mechanism (e.g., Churchland, 2002), as compared with the political scientist, economists and sociologists who advocates socio-political system, neoliberalism, capitalism or socialist superstructure respectively (e.g., Travers, 2010). As the legal domain advocates societal morality, it is also at the same time very much understood that law shapes the society. Society is a matter of group and communities which are based on hierarchy and hence the authority, characteristically, shapes the legal theories and perspectives too (Nonet \& Selznick, 2007). In our hegemonized space which is possessed by the social orders and hierarchies, the actions are attributed around the prevalent notions of rationality.

The discourse of neuroscience or any other socio-political and economic factors as determiner of action never emerge as prime facie, they are embedded in our general life and any emergence of act is taken as will full and controlled by the actor. Some of the studies (e.g., Nahmias, Shepard, \& Reuter, 2014) presented participants with scenario where it was shown that neuroscientist can predict $100 \%$ of every decision of the person that he/she is going to make and it will be predicted ahead of time based on the activities of the brain. Despite this, people were shown to attribute free will to the agents against all the evidence corresponding certainly to the neuroscientific prediction (see also Rose, Buckwalter \& Nichols, 2017). Our taken for granted behaviour and assumption about the others depends upon our adaptation with the cultural linguistic flows which comprises varieties of discursive roles and practices. The person who finds uneasy to talk in the group of intuitive and loses his flows may be diagnosed informally and, in a sweep, aside by the people as anxious, asocial, shy, or autistic. Maybe the 
person is also deprived of his aptitude to solve the problem in crisis due to this one single cause. What matters is the trend of discourses uncritically adapted by the agents and the observer.

Neuroscience operates through its techniques, as these are in the discourse as a post event phenomenon. Evidence about the free will, as it showed that its existence is moderated by the culture, personality, situation and cognitive reflection, especially in the legal domain depends upon its usefulness rather than theory as such. Neuroscientific theories are built upon their usefulness to some domain, for example, diagnosis of mental illness, dysfunctions in the bodily movements or the legal domain where evidences cater to the assumptions about the defendants as legally responsible or not, for their actions. The rise in the belief about the neuroscientific prediction of human behaviour, still cannot be a force which seems to have a capacity to build up a rubric of understanding human acts. There were some researchers who belongs to the disciplinary background, such as, biomedical, psychology, neuroscience, law, electrical and computer engineering and psychiatry (see Kiehl et al., 2018), and used independent component analysis and machine learning techniques, to demonstrate the utility of using brain-based measures of cerebral aging in order to predict recidivism. On the similar lines, the interdisciplinary connections of this kind are in the process of creating predictive models based on the fMRI-based brain study of the incarcerated individuals in order to give better treatment or rehabilitation inputs. Those working in the area of predicting the criminal acts of the confined individuals may give indication to the legal domain whether to make them part of the society or carry on with their imprisonment. Nonet and Selznick (2007) noted that legal domains are in some way responsive institutions which are not too flexible and adaptive to the dominant forces. They stated that "a responsive institution retains a grasp on what is essential to its integrity while taking account of new forces in its environment” (p. 77). Law as its role is practical and empowering accounts to the society.

The direction that laws provides in its judicial description is none other than the moral codes of the social system passed from generations and got established as a structured social knowledge. Law takes from society and uses its codes to regulate it. Free will as it seems to be inbuilt in us from the societal influences gets its meaning from the legal influence which socialized us in the form of common-sense understanding. The social agents get a clear understanding of social form, structure and morality from the law in action. So, the role of neuroscience as it seems to be taken by the law gives to it a codified meaning from which the society gets its discursive clarity, that is a set pattern of use of technical knowledge well defined in the local space whether critically or affirmatively. For example, even people are not very 
much familiar with the actual scientific use of fMRI but they inculcate into their everyday interaction the socially constructed meaning of terminology, in order to make it familiar with their expression, meaning making and activities around. Thus, it is not to say that the socially constructed knowledge of the techniques of brain scanning or any other biomedical terminology alter the fact about them, only the social meaning becomes more confined to the general understanding of people. What is social is legal and what is legal feedback against society in a loop. It is not that society will decide about the legal responsibility but it is the will and autonomy of the law to determine and attribute the sanity and responsibility based on the psychological capacity and mental state of the person. The two conditions for penalty comprise objective, the standard one in which the person acts consciously and the subjective one comprising intention and negligence factor of the model penal code determine (see Bertelsen, $2011)^{6}$. The legal expert and judges look into the evidence provided by the experts in order to make sense of the case and come to the conclusion about the penalty.

Free will is determined by the belief people hold but its authenticity is established by the autonomy of law which has for a long time given space to the individual strength and weakness to avoid the act prohibited by society and law and to perform what is sanctioned by both respectively. The question about where free will comes and how the brain operates to lead the person to act is pragmatically handled to the capacity and standard established by the law in consensus. We are not our brains and what we do is done in the name of our will and not our brain. Laws don't see beyond the wall but incriminate on the basis of what is doable and notdoable under the general capacity of human beings. Why did the person act violently this time and before and how does others holding similar capacity vetoed from acting in that direction? These are the questions that make the definition of free will sanctioned by the legal domain a more powerful buffer from the perspective which tries to position the universal notion of free will.

Law doesn't seem to lock itself in the resolution of something freely willed or uncontrollably determined by the causes beyond the human capacities. It is another matter how the legal domain defines human capacities and where it draws its boundary, lest it becomes open to the diverse research from various social and human sciences. Any explanations from the dominant sciences about the phenomenon under observation claim the theory pertinent to their disciplinary domains. Similarly, for the law, it is a myth that it will be changed by something claiming to be a dominant science or an authentic science. Law will see every new

\footnotetext{
${ }^{6}$ Supra 48

Dr. Chetan Sinha, OP Jindal Global University, Sonipat

Email: sinchetan@gmail.com
} 
explanation from its perceptive and pull under its boundary all other explanations in prevalence. The intention-action debates had created more confusions than clarity in the social sciences and philosophical domains which further extended to the legal domain, though, the latter resolved it succinctly without much falling into the confusions of infinite regress of causes. What is most obvious and intuitive both at the individual and collective level matters more than an attempt to locate the final cause which doesn't have necessarily a linear path, as defended by Wegner (2002) in his illusion of conscious will, and it is undecipherable (see Baumeister, 2008). If any cause is undecipherable, it has nothing to do with the legal domain because it corresponds to the volatile category whose boundary is not clear and the legal domain will be then taken for granted and undervalued. To avoid this lack of trust, lower confidence and anarchism, judiciary look for obvious cause and has very less to do with the uncontrollable passive stimuli which shaped the individual personality and the subjectivity. The concrete cause is a necessity for the judiciary to survive. Now, if the same cause is interpreted as determined and as a function of an individual sociobiological system, the legal domain looks for avenues where the majority of individuals would have done or if the defendant could have done otherwise. Not choosing the alternative options or making choice in the circumstances when other would had avoided activate the folk psychological notion about the person's intentions which comes naturally into the socio-legal collective attributing process where most of the people unanimously infer about the person's intention and conscious choice making together with the removal of evidence which may had put the person directly involved into that choice making which is contrary to the embedded moral values of the society. This implies that liability is the given legal ownership for the rationality of which the person is capable of behaving and further acting on the social world. If this action is observed to be in the rational control of the person and just not the functionally driven behaviour, liability is imposed based on the emergent collective sense of responsibility on the part of law and its protagonists.

\section{Neuroscience, neoliberalism and free will}

Neuroscience is also the product of modernity and connects well with the rising neoliberalism ${ }^{7}$, apart from it being the product of biological science. Both science and its branches such as biological sciences, rose to the height of scientific endeavour to understand

\footnotetext{
${ }^{7}$ The sense of modernity and neoliberalism are not taken as exact socio-political values but they also have one critical connection where the emphasis on individualism, objectivity, ability and meritocracy are profound. Modernity, however, for oppressed social groups in countries like India emancipated them more than the dominant traditional values. Neuroscience with its findings may either situate the marginalized as some beings having particular brain structure or it may liberate the powerless from the long historical construction of bodily oppression and reconstruct them as like all other human beings having different sociocultural experience.

Dr. Chetan Sinha, OP Jindal Global University, Sonipat

Email: sinchetan@gmail.com
} 
human and other organisms separated themselves from the social and theological view of the human. The aim was to construct a scientific, empirical and reliable view rather than the metaphysical one with little certainty and more obscurity. In this process to establish a replicable science, the neglected aspects of any species were its social and cultural demands under which the organisms shape themselves, what biological scientists call species specific behaviour, a functional and deterministic notion of culture ${ }^{8}$, cut off from the wilful action out of available alternatives. The way of inferring human nature in the pre-modern time in different cultural and geographical locations as compared with the modern times were based on the different kinds of struggles. In the case of the former, it was the struggle to place the scientific truth against the theological and in the latter case it was something like falsification of scientific theory with new evidence. The engagement of one person with the scientific truth was individualistic in the pre-modern times as compared to the clash of novel ideas in the latter case. The way invasive techniques or the mapping of the skull and brain was done in the previous times was based on the individual interest as compared to the rise of techniques to get the exact picture of the body to give the exact explanations quite spread among the students favourably forming the new agenda for capitalism and market regulations. The quick rejection of the novel individual idea or truth by the society regulated by the dualistic theology took the new turn where it was regulated by the market and capitalism. In the present it has worn a new attire in the name of methodological individualism, mindless statistics and number adoptions, merits and hence neoliberalism. This systematic excursion of neuroscience into many domains from psychiatry to marketing, which is happening at larger scale now, and connecting to different domains core area, is legitimizing the dominant metatheory and indicating an everexpanding capitalism and the extension of colonization of mind. Though legal domain is hopeful to keep a check on these ever expanding medical and neural categorization of free will, it's method of checks are itself at the risk of methodological and technological supremacy without much ado to the inherent problem attached to their taken for granted aspects. The irony in which neuroscience presents a deterministic role of the brain, at the same time presents the possibility of brain cure through various pharmacological and medical treatment. The neuro workers who visualize the brain and make effort to change for whatever purpose like cure, change of mind, persuasions, manipulations, somewhere paradoxically portrays the system of power where the powerful operate on the powerless. In the psychiatric domain it is the mental

\footnotetext{
${ }^{8}$ Here it is a group specific way of behaving and acting in its environment common to that species. For example, it is quite specific to humans to opt for deception. Dr. Chetan Sinha, OP Jindal Global University, Sonipat

Email: sinchetan@gmail.com
} 
patient and the psychiatrists, where the latter is powerful and through rhetoric's medical terminologies label the patients very acts. The neoliberal time is the time of individuality in the attire of community and groups and it is also a kind of deterministic context under which group, communities and everyday taken for granted interaction patterns are doubted.

The whole debate about the free will-brain compatibilism and in-compatibilism symbolizes the powerful interventions of capitalism where ironically under the neoliberal context free will is entertained and at the same time regulated under its influences. In the case of brain dysfunction, it is the free will only which outperforms the determinism in the cure. Szasz (1974) rejected anything like mental illness because the very term illness is a pathological terminology whose cause is in the objective presence of disease which is not the case with the psychiatric portrayal of a person as mentally ill who is out of the social structure and social norms and seemingly danger to the society. He asserted that mental illness is not the medical problem, whose objective platform is misidentified. It is the person's self-conversation which is good enough to give the person insight about his/her self rather than any medicine which slows down the neural firing and in no way symbolizes exactly the mental condition. Though his view was more a right wing libertarian view (Rose, 2018) ${ }^{9}$ which noted that mental illness is a metaphor and operates under the power dynamics of the socially and politically powerful.

Who has the legitimate right to infer about others without knowing the value, history, traditions of knowledge and identity? If any judgment by the jury or judges is taken without much reflection upon the life of others, there are always rooms for error. Here, errors are the wrongful placement or identification of others identity in one's prejudiced platform. This happens most of the time in the case of socio-economically powerful. How much pro indigenous is the law and neuroscience whose unescapable rhetoric laden with the observable facts has the ability to understand the subjectivity, deep seated memories of dominance and oppressions? The effort to find a link between neuroscience and neoliberalism in the legal context is both easy and hard. Neuroscience has no less rising terminology linked to specific place and activity of the brain and so the ever-rising case for its deterministic stance. It is not always that the world goes by one's will but it is most of the time otherwise where one goes by the world's will. If the will of the society is neoliberalism, all the units and institutions of society acts as per that will in the name of individual will. It is the enactment in collectivity, a

\footnotetext{
${ }^{9}$ Rose, N. (2018): Our Psychiatric Future. UK: Polity Press
} 
kind of societal determinism or social acts in norm, disguised as will. In any case the will persists. For example, if one wants to be in solitude, which in any way not the general societal act, the whole agenda of remaining in solitude will be observed as asocial which linger on the individual too. Law understands that societal will and keeps check on it. Like psychological science, law also has an operational definition of free will which comprises an intentionally driven act.

Neoliberal times are not as concrete as a modernist outlook, as it may hold subjectivity to the extent it firmly strengthens the powerful. Any act of violence by the powerful is changed as compared to any act of resistance by the powerless as violence. The definition of free will shifts with the will of resource holders and all other efforts to neutralize science is nothing but a political act of dominance. Free will, thus, is seen in a zeitgeist, where the prominent and preferred ideology, perspective or in the Kuhnian paradigm (Kuhn, 1970), people's general understanding about oneself and others matters. There was a time when behaviour matters more than what was happening in the person's mind. Now, despite the mind being subjective, difficult to interpret and unobtrusive, we have full confidence that it matters. In law, human behaviour without the understanding of mind leads to no concrete conclusion. Few decades back, to understand the mind people relied on self-confession and language, in the current times it is the brain. In both the cases the interpretations framed in the context matters. So, it was never the 'as it is' picture of something under observation but the engagement and interpretations of the phenomenon through the perspectival lens of the agents influenced by the legal paradigms. It is not either acting subtracted from the mind or vice versa. Both act and mind complement in the legal decision making.

Law in both the cases needs concrete and tangible observables. So, even the discourse in mind in the legal domain implies something concrete, assertive and should have the virtue to be empirically captured. This is also a matter of interpretation and consensus as what is observable and how it must be interpreted. Berkeley's ${ }^{10}$ tree falls somewhere but not noticed can either be interpreted as a tree that doesn't exist because one was ignorant about it or it very much exists despite someone's ignorance. Similarly, for any legal case, if a witness keeping aside his mental framework only describes what was observed which further interpreted by the judges as a matter worthy enough to prove the defendant as not innocent or the crime happened but no one to be accused as evidence is not sufficiently available. The neuroscientific edifice is a determiner of intention and acts where the linear path is followed where brain is the primary

\footnotetext{
${ }^{10} \mathrm{https} / / /$ plato.stanford.edu/entries/berkeley/

Dr. Chetan Sinha, OP Jindal Global University, Sonipat

Email: sinchetan@gmail.com
} 
mover but for the law the primary mover is the acts on the linear pathways. In the social science debates, linearity is a reductive stance in order to be on the forefront of clarity rather than enmeshed with the varieties of variables and leading to nowhere. This reductive stance is very much embraced by the legal domain in decision making. Being prescriptive about what is happening in the person's mind or its content, as it doesn't show anything but only what is communicated through language consistency across situations, implicit and explicit associations, or in the folk psychological understanding of those acts. Though rejecting what is in the mind, social psychologist Forgas (2003) aptly stated that, "it is not implicit associations but explicit behaviour that are prejudiced and discriminatory, and it is behaviours, not implicit thoughts, that represent a legitimate social and legal problem" (p. 255). It is also the case that the very act is taken as a cause behind the victims' harm, rejecting all other causes behind, even neuroscientific. In the mundane situation, the spontaneous and taken for granted acts, can be called as a result of brain habituation in a social context, and therefore, what others do in a collective context in an automatic fashion, becomes the sign of those automatically approved acts. The agenda is to show that one acts in a context, which seems to be ecologically valid as others are also in the process of restraining what is not approved and doing what is approved.

Neoliberal times are the times of individualism, profit and merit but they are also the times when something intangible regulates the whole course of society. The notion of free will is no more taken as illusion but the will is actually seen in terms of globalization and market. Though the essence of free will is situated in the conscious act of the person, neoliberalism seems to nourish those acts more for profit of the powerful and strict social class divide then is seen among the masses. So, to be conscious of one's act is a kind of global consciousness and if one is not able to be conscious of his/her act, it is more or less an effect of the imposed or ascribed will of the powerful. For example, in the case of living people who follow religion, and ascribed as religious but after death there is no consciousness of what one was doing or practicing, then they have no religion. Religion is also doing or practicing together with being conscious of what one is doing, so if one is not conscious, he doesn't have religion and all other attempts by the society to dispose of the body through some religious rituals is not the religion of the person who died.

Similarly, for the context under which the person operates is a conscious will of the person and if the person loses consciousness in the folk psychological sense his/her responsibility becomes the responsibility of the conscious society. Like an Adam Smith's "impartial spectator" who is aware of both social norms and his/her motivation, acts as a kind of judge 
between himself/herself and those with whom he/she live (see Jahoda, 2007, p. 34), and as noted by Chomsky that Smith advocated that the people should be free without any control of authoritarian institutions and neither they should be subjected to things like division of labour which destroys them (Chomsky, 2013). However, neoliberalism operates on individuals directly but through the indirect socio-political waves. The impact of societal values on individuals is immense and it also decides the choice value of an individual. The automatic selection of available options out of many or limited by the choice depends upon the objective availability of choices and one's position on the societal ladder. How the neuroscience can be apart from these big pictures of humanity where each and every act surmounts to the heavy duty of neural networks or neurons and exactly what Vygotsky and Luria (1993) indicated them to be a higher mental functioning as a consequence of the historical and cultural processes of discontinuities and continuities with new socio-cultural interactions and activities.

In conclusion, understanding free will in the modern and neoliberal times is different from the traditional and conservative period of time. The incompatibility of experiences in these times contribute to the plurality of approaches to understand the free will. Most of the time, in everyday debates, free will is contested in a popular mode of thought, like the dominance of intuitive view which construct the notion of free will in terms of wholesome individual responsibility, as compared with the reflective view which seems to be utilitarian, construct the free will in terms of contextual determinism ${ }^{11}$. The neoliberal turns in the history of law, individualized the free will, though free will is symbolized in the collective struggle against the power also. The idea of alternative choice making and rational human beings have been critically dealt in many of the critical social sciences, as it was observed in many situations that people offered resistance to the oppressive policies and suffered both the physical and psychological injuries. In the universal language of free will, there is a little space for ideas that people are acting against their own egotistic ends, except in some social science and social psychological literature on altruism and helping. How come the individual brains started operating as a singular brain in a collective situation? Neuroscience has few explanations for this kind of question (see Lieberman, 2007). It is the brain which is shaped in some culture, as it is a passive object capable of changing its structure as per the environmental demands. As experiences are also a matter of sociocultural registration, it may be conjectured that the human brain accordingly appropriate itself with the series of neural firings in some prominent area when exact or similar situations arise.

\footnotetext{
${ }^{11}$ See also supra 55

Dr. Chetan Sinha, OP Jindal Global University, Sonipat

Email: sinchetan@gmail.com
} 
Overall, it is observed that when issues of inequality, injustice or indignity arises, who are the people coming forward to offer resistance and who do not show situational influence on the brain. The researchers interested in the neural perspective of free will naturally adhere to the brain determinism and those who think it is the social construction have a different approach to understand the groups free will. If despite the differences in the sociocultural underpinnings and brain structure, if the person attempts to choose an alternative path, it's a free will, as it happens in the opposite cases where one commits crime despite the availability of other options in the same socio-cultural situations.

\section{References}

Ajzen, I., \& Madden, T. J. (1986). Prediction of goal directed behaviour: attitudes, intentions, and perceived behavioural control. Journal of Experimental Social Psychology, 22, 453-474.

Baumeister, R. F. (2008). Free will in scientific psychology. Perspectives on Psychological Science, 3, 14-19.

Baumeister, R. F. (2008). Free will in scientific psychology. Perspectives on Psychological Science, 3, 14-19.

Baumeister, R., Mele, A., \& Vohs, K. (Eds.). (2010). Free will and consciousness: How might they work?. Oxford University Press.

Bertelsen, P. (2011). Intentional activity and free will as core concepts in criminal law and psychology. Theory \& Psychology, 22 (1), 46-66.

Chomsky, N. (2013). On anarchism. London: Penguin.

Churchland, P. S. (2002). Brain-Wise: Studies in neurophilosophy. Massachusetts: The MIT Press.

Cover, R. M. (1986). Violence and the word. Yale Law Journal, 95, 1601-1629.

Feltham, O., \& Clemens, J. (2003). An introduction to Alan Badiou's philosophy. In O. Feltham \& J. Clemens (Eds.), Infinite thought truth and the return to philosophy (by Alain Badiou). London and New York: Continuum.

Fischer, J. M., Kane, R., Pereboom, D., \& Vargas, M. (2007). Four views on free will. Blackwell Publishing. 
Fischer, J. M., Kane, R., Pereboom., \& Vargas, M. (2007). Four views on free will. Oxford: Blackwell Publishing.

Forgas, J. (2003). Why Don't We Do It in the Road...? Stereotyping and Prejudice in Mundane Situations. Psychological Inquiry, 14(3/4), 251-257. Retrieved June 20, 2021, from http://www.jstor.org/stable/1449684.

Foucault, M. (1977). Discipline and punish: The birth of the prison. New York : Pantheon Books.

Frankfurt, H. G. (1969). Alternate possibilities and moral responsibility. Journal of philosophy, 66 (23), 829-839.

Hannikainen, I. R. (2019). For whom does determinism undermine moral responsibility? Surveying the conditions for free will across cultures. Frontiers in Psychology. doi: 10.3389/fpsyg.2019.02428.

Hook, D. (2007). Foucault, psychology and the analytics of power. New York: Palgrave Macmillan.

Jahoda, G. (2007). A history of social psychology: From the eighteenth-century Enlightenment to the Second World War. Cambridge University Press.

Kenny, A. (2011). Freewill and responsibility. UK: Routledge.

Kiehl, K. A., Anderson, N. E., Aharoni, E., Maurer, J. M., Harenski, K. A., Rao, V., ... Steele, V. R. (2018). Age of gray matters: Neuroprediction of recidivism. NeuroImage: Clinical, 19, 813-823. https://doi.org/10.1016/j.nicl.2018.05.036.

Kuhn, T. S. (1970). The structure of scientific revolutions. Chicago: University of Chicago Press.

Lakoff, G., \& Johnson, M. (1999). Philosophy in the flesh: The embodied mind and its challenge to Western thought. New York: Basic Books.

Lieberman, M. D. (2007). Social cognitive neuroscience: A review of core process. Annual Review of Psychology, 58, 259-289.

Nahmias, E., Morris, S., Nadelhoffer, T., and Turner, J. (2005). Surveying freedom: folk intuitions about free will and moral responsibility. Philos. Psychol. 18, 561-584. doi: 10.1080/09515080500264180.

Nahmias, E., Shepard, J., \& Reuter, S. (2014). It's OK if 'my brain made me do it': People's intuitions about free will and neuroscientific prediction. Cognition, 133(2), 502-516. 
Nichols, S., and Knobe, J. (2007). Moral responsibility and determinism: the cognitive science of folk intuitions. Nous 41, 663-685. doi: 10.1111/j.1468-0068.2007. 00666.x.

Nonet, P., \& Selznick, P. (2007). Law \& society in transition: Towards responsive law. London: Transaction Publishers.

Pardo, M. S., \& Patterson, D. (2017). The promise of neuroscience for law: 'Overclaiming' in jurisprudence, morality, and economics. . In Patterson, D., and Pardo, M. S. (2017). Philosophical foundations of law and neuroscience (pp. 231-248). UK: Oxford University Press.

Pereboom, D. (2001). Living without free will. Cambridge: Cambridge University Press.

Rose, D., Buckwalter, W., \& Nichols, S. (2017). Neuroscientific prediction and the intrusion of intuitive metaphysics. Cognitive Science: A multidisciplinary Journal, 41, 482-502.

Rose, N. (2018): Our Psychiatric Future. UK: Polity Press.

Scarry, E. (1985). The Body in Pain: The Making and Unmaking of the World. Delhi: Oxford University Press.

Shariff, A. F., Schooler, J., \& Vohs, K. D. (2008). The hazards of claiming to have solved the hard problem of free will. Are we free? Psychology and free will, 181-204.

Szasz, T. (1974). The myths of mental illness: Foundations of a theory of personal conduct. New York: Harper Paperback.

Teo, T. (2015). Critical psychology: A geography of intellectual engagement and resistance. American Psychologist, 70(3), 243.

Travers, M. (2010). Understanding law and society. New York: Routledge.

Vohs, K. D., \& Schooler, J. W. (2008). The value of believing in free will: Encouraging a belief in determinism increases cheating. Psychological science, 19(1), 49-54.

Vygotsky, L. S., \& Luria, A. R. (1993). Studies on the history of behavior: Ape, primitive, and child. (V. I. Golod \& J. E. Knox, Eds.). Lawrence Erlbaum Associates, Inc.

Wegner, D. (2002). The illusion of conscious will. Cambridge, MA: MIT Press.

Dr. Chetan Sinha, OP Jindal Global University, Sonipat

Email: sinchetan@gmail.com 